\title{
The Dynamics Towards Multiple Strategic Options: A Conceptual Approach
}

\author{
Marc Logman
}

Instima (Professional Marketing Institute in Belgium), and UAMS (Management School of University of Antwerp), Belgium

\begin{abstract}
Ambidextrous strategies are strategies in which multiple strategic options are combined (for instance innovation and cost leadership). This paper shows that various companies often end up in following an ambidextrous strategy, due to a typical evolution in "contradictions" that characterize their strategic problem context. Often a company starts facing dichotomies in the beginning, while facing paradoxes in a later stage. Such a dynamic trajectory is illustrated, using AMD as a case study. The case study shows that an ambidextrous strategy is often not a choice, but the result of a dynamic process with no other choice left.
\end{abstract}

Keywords: Ambidextrous, strategy, contradictions.

\section{INTRODUCTION}

A competitive advantage identifies what makes the company distinctive from its competitors. Often, simple typologies or models such as Porter's generic strategies are used to define them (Collis and Rukstadt [1]; Stonehouse and Snowdon [2]).

The Porter model distinguishes three competitive positions: cost leadership (price orientation), differentiation (benefit/value orientation) and focus (niche orientation). However, as Jones and Butler [3] showed, there may be conditions in certain industry settings in which multiple strategies are simultaneously achievable, leading to what are called "ambidextrous strategies". There are however substantial differences between the "differentiation + cost + broad focus" strategy and the "differentiation + cost + narrow focus" strategy, with respect to their impact on many environmental, strategic and performance variables (Miller and Dess [4]).

The study of Sarkees and Hulland [5] shows that an ambidextrous strategy has a positive effect on four dimensions of performance: revenues, profits, customer satisfaction, and new product introductions. Each strategic option itself is even characterized by an ambidextruous nature. For instance, cost leadership today is about managing operational costs, while at the same time ensuring energy and ecological friendliness and dealing with new technologies. A popular post-Porter model is Kim and Mauborgne's value innovation framework $[6,7]$ driven by the idea of blue and red oceans (see also Logman [8]). The framework also goes fundamentally against the idea that a company must focus either on cost leadership or on differentiation. As Kim and Mauborgne state: "Value innovation is created in the region where a company's actions affect both its cost structure and its value proposition to buyers". Therefore, value innovation is ambidextrous by nature.

*Address correspondence to this author at Instima (Professional Marketing Institute in Belgium), www.instima.be and UAMS (Management School of University of Antwerp), Belgium;

E-mail: marc.logman@skynet.be
Driven by a rapidly changing business context and the many faces of competition, various companies are even forced today to use an "ambidextrous strategy", in which cost leadership and other strategic options such as differentiation are combined (Sarkees and Hulland [5]). This means it is no longer about choosing for an ambidextrous strategy, but being forced to. This leads to the first proposition of this research paper.

\section{P1. Combining multiple strategic options at the same time (as in an ambidextrous strategy) is not a result of choice but of destination.}

The dynamic trajectory towards an ambidextrous strategy depends on the historical competitive position. Some companies move from a benefit to a more cost oriented position (such as Goodyear). Others move in the opposite direction, from costs to more benefits/value (bvb. Boeing) (Linder and Cantrell [9]). These moves are characterized by multiple risks (Slywotzky and Drzik [10]).

As Hamel [11] observes, "creating the right set of paths" is more important than "assembling grand strategies". Due to path dependence, taking one road often precludes taking others and determines where you end up (Sterman [12]). Every decision you make as a company may automatically narrow your possibilities, until the only possible place for your business is exactly where you are (Gilmore and Pine [13]).

Various companies often end up in following an ambidextrous strategy, due to a typical evolution in "contradictions" that characterize their strategic problem context. The following contradictions can be distinguished (Stacey [14]):

- A dichotomy: a polarised opposition, requiring an "either/or" choice (one alternative being more attractive than the other).

- A dilemma: a polarised opposition, requiring an "either/or" choice between two equally unattractive alternatives. 
- A duality: a polarised opposition, that can be resolved by thinking in terms of a "both/and" choice (separating the different alternatives in different times or spaces).

- A paradox: presence of opposing alternatives at the same time and space, requiring a simultaneous "both/and" choice.

Resolutions in dealing with dualities and paradoxes, characterize integrative thinking in management. As Martin [15] states: "It is about the ability to face constructively the tension of opposing ideas and instead of choosing one at the expense of the other, generate a creative resolution of the tension in the form of a new idea that contains elements of the opposing ideas but is superior to each".

In practice, a company may face dichotomies in the beginning while ending up with paradoxes in pursuing its strategic roadmap. Parallel to this evolution in its strategic problem context, the company often evolves from a single strategic option to a more ambidextrous option. This leads to the second proposition of this research paper.

\section{P2. The dynamic trajectory towards an ambidextrous strategy is driven by the dynamics in contradictions characterizing the strategic problem context.}

\section{RESEARCH METHODOLOGY}

To test and illustrate the propositions, a case study approach is used, focusing on AMD as a single case. Single cases offer the opportunity to provide a more in-depth analysis and explore complex and longitudinal problem contexts (Yin [16]).

AMD operates in the microprocessor industry, which is a rapidly changing and complex industry. It is an industry highly dominated by Intel. To obtain reliable strategic information about strategic issues at AMD, Form 10-K annual reports (archival information) over a four-year period (2005-2008) were used. A Form 10-K report is an annual report required by the U.S. Securities and Exchange Commission, that gives a comprehensive summary of a company's performance. As Nadkarni and Narayanan [17] notice, many researchers have used annual reports to assess causal reasoning. Moreover these authors observe that strategy researchers consider the contents of the $10-\mathrm{K}$ report to be reliable. An interesting item in the $10-\mathrm{K}$ reports is item 1A: "risk factors". Here the company describes what could go wrong, what are likely external effects, possible future failures and other risks. It reveals important insights into strategic issues.

\section{RESEARCH FINDINGS}

Analyzing AMD's Form 10-K reports over the last couple of years, we observe an evolution in contradictions.

\section{Stage 1: Facing a Dichotomy}

Until the late nineties, clockspeed performance was the main value dimension. Toward the end of the decade, the market began to place less value on speed and became reluctant to pay for it (Burgelman and Grove [18]). Hence, clockspeed became a commoditization driver. This left AMD the choice of either following the commodity cycle or countering it. The main problem with following commoditization is that it often leads to a profit squeeze. As a result, many companies preferred replacing clockspeed by new value dimensions, such as power consumption and communication capabilities. Intel began to focus on mobile PC microprocessors (under the Centrino name). AMD, started making similar moves and started providing processing solutions for the computing, graphics and consumer electronics markets. AMD is committed to lead the world to energy-efficient processing and to developing "innovations" that reduce energy use, increase power efficiency and solve customer problems.

\section{Stage 2: Facing a Dilemma}

The choice between following commoditization (focusing on price) or countering it by pursuing value innovation, turns out to be a dilemma in a later stage, as value innovation may include unattractive risks as well.

It is formulated in AMD's Form 10-K reports (2006, 2007) as:

\begin{abstract}
"The success of our business is dependent upon our ability to introduce products on a timely basis with required features and performance levels that provide value to our customers and support and coincide with significant industry transitions."
\end{abstract}

Moreover, AMD states that:

"Products as complex as those we offer may contain defects or failures when first introduced or when new versions or enhancements to existing products are released. We cannot assure you that, despite our testing procedures, errors will not be found in new products or releases after commencement of commercial shipments in the future, which could result in loss of or delay in market acceptance of our products, material recall and replacement costs, delay in recognition or loss of revenues, writing down the inventory of defective products, the diversion of the attention of our engineering personnel from product development efforts, defending against litigation related to defective products or related property damage or personal injury, and damage to our reputation in the industry and could adversely affect our relationships with our customers."

It shows that both a commoditization follower and a value innovator face the same risk, that of profit squeeze (the first by prices becoming too low, the latter by costs becoming too high). It characterizes the dilemma at that stage.

\section{Stage 3: Facing a Duality}

After some bad experiences, AMD became perfectly aware that missed innovation opportunities could lead to a new wave of price pressure. 
In this context AMD states:

"If we are delayed in developing or qualifying new products or technologies, such as what occurred with the multiple delays in the launch of our R600 GPU for the high-end category of the PC market, we may lose credibility and our competitors may be able to take advantage of these delays by launching higher performing products before we do, which could cause us to lose market share and force us to discount the selling price of our products. Delays in developing or qualifying new products can also cause us to miss our customers product design windows". "If our customers do not include our products in the initial design of their computer systems, they will typically not use our products until at least the next design configuration. The process of being qualified for inclusion in a customer's system can be lengthy and could cause us to further miss a cycle in the demand of end-users, which also could result in a loss of market share and harm our business" (again being forced to lower prices in a later stage).

It shows the duality: choosing for value innovation in a first stage, possibly being followed by a price focus (being forced to) in a later stage. The ambidextrous nature of the strategy at that stage however is sequential, meaning one strategic option is followed by another opposite option.

\section{Stage 4: Facing a Paradox}

Contradictions however become even harder to deal with in the final stage of a typical strategic trajectory. At that stage contradictions often become paradoxes, as opposite options have to be dealt with at the same time. An important paradox is that of competing today and tomorrow at the same time (Logman [19]).

In October 2006 for instance, AMD completed the acquisition of ATI. This allowed the company to supply 3D graphics, video and multimedia products and chipsets for personal computers or PCs, including desktop and notebook PCs, professional workstations and servers and products for consumer electronic devices such as mobile phones, digital TVs and game consoles. As a result of the ATI acquisition, AMD felt a competitive disadvantage was created as Intel might start giving AMD's competitors in the graphics market preferential access to interface or other useful information. Moreover, AMD anticipated that third-party companies might feel discriminated as AMD started supplying a significantly greater amount of graphics products on its own. It shows that the creation of a new "competitive advantage", may create "competitive disadvantages" that have to be accepted at the same time.

Lastly, at the 2008 Mobile World Congress, the company showed that it is perfectly aware that pure mobile data transmission will become a commodity. It therefore anticipates to new commoditization moves, by investing in new graphics and multimedia technologies such as 3D graphics, mobile TV and video streaming for mobile phones and other handheld devices. These growth moves will certainly be accompanied by new important paradoxes.

Paradoxes force the company to pursue multiple opposing strategies at the same time, leading to an ambidextrous strategy, in which value is created on one hand and destroyed on the other hand at the same time. Fig. (1)

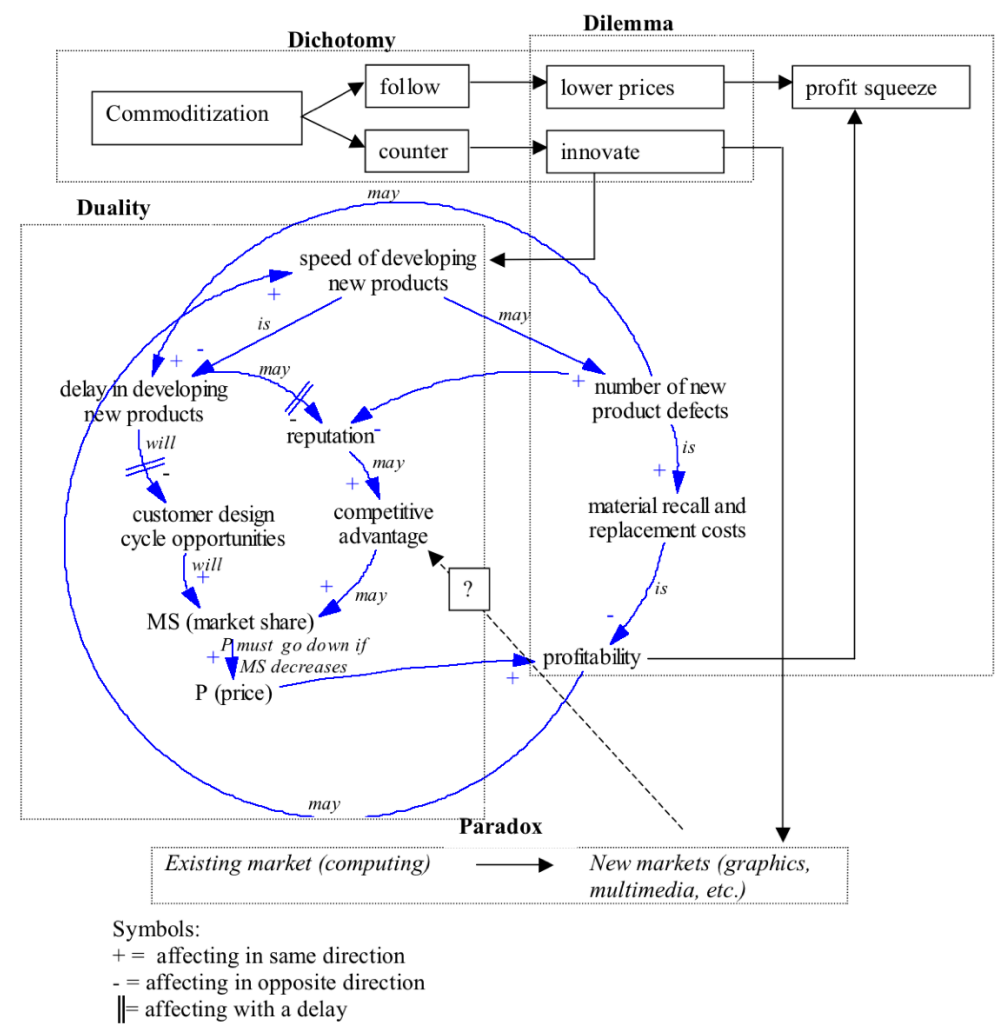

Fig. (1). Contradictions in AMD's strategic trajectory. 


\begin{tabular}{|c|c|c|c|}
\hline Dichotomy & Dilemma & Duality & Paradox \\
\hline$\downarrow$ & $\checkmark$ & $\nabla$ & $\nabla$ \\
\hline $\begin{array}{l}\text { Certain single } \\
\text { strategic choice }\end{array}$ & $\begin{array}{l}\text { Uncertain } \\
\text { single strategic } \\
\text { choice }\end{array}$ & $\begin{array}{l}\text { Sequential } \\
\text { ambidextrous } \\
\text { choice of }\end{array}$ & $\begin{array}{l}\text { Simultaneous } \\
\text { ambidextrous } \\
\text { choice of }\end{array}$ \\
\hline
\end{tabular}

Fig. (2). Dynamic process towards an ambidextrous strategy.

characterizes the four contradiction types of AMD's strategic trajectory.

The causal map shows that its complexity is not only characterized by the number of variables and the connectiveness (causal linkages) among all variables involved, but also by the connectiveness among various temporal and logical modes of thinking ("must be", "is", "may be" and "will be" modes).

\section{CONCLUSIONS, IMPLICATIONS AND FUTURE DIRECTIONS}

The insights in this paper show that as a company grows, it will face contradictions that will evolve from pure dichotomies to paradoxes. The shift in contradiction types will force the company to evolve from a single strategic choice to an ambidextrous strategy, in which multiple strategic options (even opposing ones) are combined at the same time. Therefore, an ambidextrous strategy is often not a choice, but the result of a dynamic process with no other choice left. This dynamic evolution is illustrated in Fig. (2). It confirms the two propositions defined in section 1 .

However, it should be clear that this study has important limitations as well, requiring further research. The study relies upon archival information, portraying how AMD observes and formulates the strategic risks perceived. Written documents may differ from what is actually going on in the minds of all decision makers involved. Various decision makers may have a different perception about the sequence of and connectiveness among certain environmental concepts. This may be due to a difference in cognitive time position (using different time angles). A decision maker may use the past, the present or the future as the "starting point" for strategic reasoning. For instance, a future oriented decision maker will think and reason in a retrospective way, using a future vision as the starting point for reinterpreting present and past. A difference in time angle may imply that some strategic issues are perceived to be "intratemporal" in nature for some decision makers, while being "intertemporal" for other decision makers.

\section{REFERENCES}

[1] Collis DJ, Rukstad MG. Can you say what your strategy is? Harv Bus Rev 2008; 86(4): 82-90.

[2] Stonehouse G, Snowdon B. Competitive advantage revisited: Michael Porter on strategy and competiveness. J Manage Inquiry 2007; 16(3): 256-73.

[3] Jones GR, Butler JE. Costs, revenue, and business-level strategy. Acad Manage Rev 1988; 13(2): 202-13.

[4] Miller A, Dess GG. Assessing Porter's model in terms of its generalizability, accuracy and simplicity. J Manage Stud 1993; 30(4): 553-85.

[5] Sarkees M, Hulland J. Innovation and efficiency: It is possible to have it all. Bus Horiz 2009; 52: 45-55.

[6] Kim WC, Mauborgne R. Creating new market space. Harv Bus Rev 1999; 77(1): 83-93.

[7] Kim WC, Mauborgne R. Blue ocean strategy. How to create uncontested market space and make the competition irrelevant. Harvard Busines School Press: Boston/Mass 2004.

[8] Logman M. Logical brand management in a dynamic context of growth and innovation. J Product Brand Manage 2007; 16(4): 25768.

[9] Linder J, Cantrell S. Changing business models: surveying the landscape. Working paper Accenture Institute for strategic change, May 2000.

[10] Slywotzky A, Drzik J. Countering the biggest risk of all. Harv Bus Rev 2005; April: 1-11.

[11] Hamel G. Leading the revolution. Harvard Bus School Press: Boston 2000

[12] Sterman JD. System dynamics modeling: tools for learning in a complex world. Calif Manage Rev 2001; 43(4): 8-25.

[13] Gilmore JH, Pine II BJ. Authenticity, what consumers really want. Harvard Business School Press: Boston 2007; pp. 180-5.

[14] Stacey RD. Strategic management and organisational dynamics. Prentice Hall: USA 2007; pp. 14-5.

[15] Martin RL. The opposable mind: How successful leaders win through integrative thinking. Harvard Bus School Press: Boston 2007.

[16] Yin R. Case study research: design and methods. Sage Publication: UK 2003.

[17] Nadkarni S, Narayanan VK. Strategic schemas, strategic flexibility and firm performance: the moderating role of industry clockspeed. Strateg Manage J 2007; 28: 243-270.

[18] Burgelman RA, Grove AS. Let chaos reign, then rein in chaos repeatedly: Managing strategic dynamics for corporate longevity. Strateg Manage J 2007; 28: 965-79.

[19] Logman M. Contextual intelligence and flexibility in today's marketing environment. Market Intell Plann 2008; 25(5): 508-20. 